\title{
OS DESAFIOS ESTRATÉGICOS DA ALFABETIZAÇÃO E LETRAMENTO NA FORMAÇÃO DE PROFESSORES DA/NA EDUCAÇÃO DO CAMPO
}

\author{
Andréa Wahlbrink Padilha da Silva ${ }^{1}$ \\ Vanessa Gonçalves Dias ${ }^{2}$ \\ Conceição Paludo ${ }^{3}$
}

\begin{abstract}
Resumo: A partir dos resultados de uma pesquisa-ação desenvolvida no âmbito do Projeto de Pesquisa Observatório da Educação do Campo/CAPES/INEP em seu núcleo no Estado do Rio Grande do Sul, o artigoanalisa parte dos dados da pesquisa, a qual foi desenvolvida junto há duas escolas da rede pública municipal, localizadas na zona rural de Pelotas no período de 2011 a 2014. O trabalho possui como foco central de discussão os processos de alfabetização e letramento na formação de professores da/na educação do campo. A coleta de dados contou com entrevistas semiestruturadas, observação participante, análise dos diários de campo. Considera-se, ao final, como principal resultado da pesquisa, está a contribuição de(re)colocar os professores como protagonistas de seus fazeres pedagógicos, e com isso a ampliação de suas condições de análise do processo de aprendizagem dos estudantes.
\end{abstract}

Palavras-chave: Pesquisa-ação; Alfabetização e Letramento; Formação de professores.

\section{LOS DESAFÍOS ESTRATÉGICOS DE LA ALFABETIZACIÓN Y LETRACIÓN EN LA FORMACIÓN DE PROFESORES DE LA EDUCACIÓN DEL CAMPO}

Resumen: A partir de los resultados de una investigación-acción desarrollado bajo el Proyecto de Investigación Observatorio de la Educación Rural/CAPES/INEP en su núcleo en el estado de Rio Grande do Sul, el artículo analiza los datos de la encuesta, que fue desarrollado en conjunto hay dos escuelas de la red municipal, ubicadas en la zona rural de Pelotas en el período 2011-2014. El trabajo tiene como eje central la discusión de la alfabetización y alfabetismo la formación del profesorado en el / en el campo de la educación. La recolección de datos incluyó entrevistas semiestructuradas, observación participante, el análisis de los diarios de campo. Es, al final, ya que el principal resultado de la investigación es la contribución de la (re) puso maestros como protagonistas de su quehacer pedagógico, y así ampliar su análisis de las condiciones de proceso de aprendizaje de los estudiantes.

Palabras-clave: Acción de Investigación; Alfabetización y; Formación Del professorado

\footnotetext{
${ }^{1}$ Mestre em Educação pelo Programa de Pós-Graduação em Educação da Universidade Federal de Pelotas UFPel, Faculdade de educação - FaE, na linha História e Filosofia da Educação, Pelotas RS.andreawahlbrink@hotmail.com

${ }^{2}$ Doutoranda na Universidade Federal do Rio Grande do Sul - UFRGS, Faculdade de Educação - FACED, na linha de pesquisa: Trabalho, Movimentos Sociais e Educação -TRAMSE, Porto Alegre - RS. vanygd@yahoo.com.br

${ }^{3}$ Doutora, professora pesquisadora na Universidade Federal do Rio Grande do Sul - UFRGS, Faculdade de Educação - FACED, na linha de pesquisa: Trabalho, Movimentos Sociais e Educação - TRAMSE, Porto Alegre - RS. c.paludo@terra.com.br
} 


\section{INTRODUÇÃO}

$\mathrm{O}$ artigo tem como objetivo apresentar o percurso teórico-metodológico da pesquisa que foi desenvolvida junto às escolas municipais da rede pública de ensino fundamental, intitulado, Observatório da Educação do $\mathrm{Campo}^{4}$, o qual, por sua vez, teve o objetivo de proporcionar o desenvolvimento de pesquisas nas escolas do campo da região Sul do Rio Grande do Sul, como também na sua relação entre os estados do sul do país, em regiões de Santa Catarina e do Paraná, através de um trabalho conjunto com as universidades: Universidade Federal de Santa Catarina - UFSC e Universidade de Tuiuti, no Paraná - UTP. De modo a pensar a realidade das escolas do campo na região Sul do Brasil, a partir de diagnósticos e intervenções pedagógicas, com ênfase na alfabetização, letramento e formação de professores.

Este trabalho foi desenvolvido em 18escolas da zona rural, sendo seis escolas em cada estado envolvido. Para tanto, o projeto contou com bolsistas distribuídos nas três instituições, composto por: doutorandos, mestrandos, graduandos e professores do ensino fundamental, promovendo a articulação entre pós-graduação, licenciaturas e escolas de Educação Básica. Integraram o projeto do Observatório da Educação do Campo - núcleo Rio Grande do Sul seis escolas do campo da região, situadas nos municípios de Pelotas, Cerrito e Piratini.

Para cada escola foi organizada a inserção de pesquisadores, envolvendo bolsistas do doutorado ou mestrado, graduandos de licenciaturas e professores da rede, que por meio de estudos de investigação-ação junto às escolas, pudessem construir ações com o coletivo da escola e da comunidade, para enfrentar as problemáticas relacionadas aos processos de aprendizagem, tais como; a alfabetização e a letramento de professores e estudantes nas escolas do campo, o estreitamento das reações entre escola e comunidade local e também a formação continuada de professores. Em especial, este trabalho tem o objetivo debater as questões que envolvem os processos de aprendizagem como a alfabetização e o letramento de alunos e professores.

\footnotetext{
${ }^{4}$ Projeto de pesquisa do Observatório da Educação do Campo - OBEDC. Intitulado: Realidade das escolas do campo na região sul do Brasil: diagnóstico e intervenção pedagógica com ênfase na alfabetização, letramento e formação de professores - modalidade em rede -RS/SC/PR. Realizado na Faculdade de Educação/FAE, da Universidade Federal de Pelotas/UFPel, Sob a orientação da Prof ${ }^{a}$ Dr. Conceição Paludo. Financiado pela CAPES/INEP.

Momento: diálogos em educação, E-ISSN 2316-3100, v. 26, n. 1, p. 96-117, jan./jun. 2017
} 
A perspectiva teórico-metodológica de abordagem da realidade é o materialismo histórico dialético (FRIGOTTO, 2000; TRIVÑOS, 1987). De acordo com Triviños (1987, p.129) "na pesquisa qualitativa com raízes no materialismo dialético, [...], o fenômeno tem sua própria realidade fora da consciência. Ele é real, concreto e, como tal, é estudado". E o tipo de pesquisa baseia-se na pesquisa-ação (BRANDÃO, 1982; THIOLLENT, 1986; MELLO, 2005), para MELLO (2005, p. 32), a pesquisa não é simplesmente uma coleta de dados do campo pesquisado para mudar a realidade de um grupo social. A pesquisa-ação é uma proposta de ruptura, a qual tem como objetivo re-significar a pratica social, avançando para que o sujeito e a sociedade possam se reconstruir, modificar e alterar suas condições de vida e de aprendizagem.

Logo este tipo de pesquisa vai ao alcance de conhecer e agir principalmente nas necessidades básicas das classes populares. Conforme enfatiza BRANDÃO (1982), a pesquisa-ação pode ser:

Um conhecimento que, saído das práticas políticas que torna possível e proveitoso o
compromisso de grupos populares como grupos de cientistas sociais, por exemplo,
seja um instrumento a mais de reforço do poder do povo. Poder que se arma de
participação do intelectual, (o cientista, o professor, o estudante, o agente da
pastoral, do trabalhador social e de outros profissionais militantes) comprometidos
de algum modo com a causa popular (BRANDÃO 1982.p.10).

Esta concepção e opção de pesquisa no espaço escolar nega a visão tradicional e tecnicista baseada numa concepção conservadora de cultura (fixa, estável, herdada) e conhecimento (como informação já processada), a ser repassado pela escola e pelos professores na forma de conteúdo. Nesta visão tradicional, os conteúdos são apresentados como neutros e inquestionáveis, e são transmitidos disciplinarmente na lógica da educação bancária. Nesse sentido, a perspectiva da pesquisa-ação, de acordo com Mello,

Traz consigo a possibilidade educativo/pedagógica para a própria formação dos educadores, na medida em que contribui para a reconstrução de nossa identidade como trabalhadores em educação. Assim, coletivamente vamos redescobrindo o prazer da pesquisa, incorporando práticas de reflexão crítica, de curiosidade investigativa incorporando procedimentos e não apenas técnicas para qualificar a atuação no espaço escolar (MELLO, 2005, p. 15).

Neste processo dialético, o processo do conhecimento tem como ponto de partida a prática social enquanto a base da teoria, que, por sua vez, deve servir para transformar a realidade. Como toda prática é essencialmente contraditória, nos processos de pesquisa é a reflexão do cotidiano que permite descobrir essas contradições e orientar novos fazeres. De 
acordo com Jara (2005, p. 54), “esse processo permite ir conhecendo as contradições e orientar novas práticas de adquirir capacidade de teorizar, de interpretar a realidade, hierarquizando as contradições e nos apropriando dos conhecimentos teóricos".

Elencamos assim, segundo os pensamentos de MELLO (2005), alguns pressupostos que orientam a compreensão de realidade e de sua investigação: 1- A realidade não é estática, está sempre em movimento, logo pode ser transformada; 2 - A realidade é construída a partir da apreensão das condições objetivas e das representações sociais dos sujeitos da investigação; 3 - A realidade é contraditória. Desta forma, a compreensão de escola, sociedade, comunidade e currículo, como processo e como movimento, nos colocam sempre o desafio da re-leitura da realidade socioeconômica e cultural, a qual estamos inseridos para, a partir dela e de sua problematização, buscarmos o diálogo com o conhecimento sistematizado.

Assim, a pesquisa-ação ao mesmo tempo em que realiza um trabalho científico, ela é humanizadora, pois, busca em seus meandros compreender causas e consequências do objetivo a ser desvelado. Ao mesmo tempo em que tem com o propósito ações e preposições construtivas, se constrói e se modifica. Nesse sentido, a escola que quer ser resistente tem como compromisso incentivar o conhecimento critico mostrando para seus educandos que o conhecimento real é aquele que constrói entendimentos sólidos para o desvelamento das questões que impedem o avançar de cada comunidade.

No mesmo sentido que MELLO (2005), o autor THIOLLENT (1986) aponta que a ênfase da pesquisa-ação está na resolução dos problemas, na tomada de consciência e na produção do conhecimento.

\begin{abstract}
A pesquisa-ação é um tipo de pesquisa social com base empírica que é concebida e realizada em estreita associação com uma ação ou com a resolução de um problema coletivo e no qual os pesquisadores e os participantes da situação ou do problema estão envolvidos de modo cooperativo ou participativo (THIOLLENT, 1986, p.14).
\end{abstract}

Deste modo, é nesse processo entre o novo e o velho nessas tensões dialéticas, que se vai construindo a concepção de formação de professores e professoras alfabetizadoras, necessárias para as escolas do Campo. $\mathrm{O}$ andamento desta pesquisa esteve sistematizado a partir das ações que foram desenvolvidas junto e em conjunto com as escolas, dessa maneira, foi pretendido desenvolver atividades de modo a permitir que ao final dos quatro anos de pesquisa, o resultado deste processo seria o de auxiliar na qualificação das práticas 
pedagógicas, proporcionando avanços qualitativos no desenvolvimento de práticas que se utilizem do letramento e da alfabetização nas escolas e nas comunidades.

Como forma de apresentação do processo investigativo desse artigo, optou-se por desenvolver a seguinte proposta: No primeiro momento a apresentação da proposta e dos contextos pesquisados, seguidos da discussão teórica da Educação do Campo e da Alfabetização e Letramento: 1.1. A escola, comunidade e sua materialidade objetiva; 1.2. Do ruralismo Pedagógico ao projeto de Educação do /no Campo; 1.3. A Educação do Campo e a alfabetização e letramento: na busca da construção da criticidade. E no segundo momento os processos de pesquisa-ação e as considerações finais: 2.1. O cotidiano das práticas escolares de alfabetização e letramento nas escolas do campo; 2.2. Os desdobramentos da pesquisa-ação na escola e na comunidade.

\section{ESCOLA, COMUNIDADE E SUA MATERIALIDADE OBJETIVA}

No ano 2011, partiu-se da discussão com o grupo de professores das duas escolas, levantando uma série de problemáticas que, segundo a compreensão dos mesmos, contribuía para o baixo índice de aproveitamento dos educandos. Dentre as problemáticas levantadas para as escolas $\mathrm{A}$ e $\mathrm{B}^{5}$ destacou-se: para a escola $A$ - dificuldades na alfabetização e letramento dos estudantes, afastamento da comunidade em relação à escola e a violência escolar; para a escola $B$ - o grande número de multirrepetentes nas etapas de alfabetização e o distanciamento das relações entre a escola e a comunidade, principalmente na apropriação da realidade social.

A respeito do resultado deste processo de levantamento das problemáticas, ambas as escolas julgaram determinante a construção de um espaço permanente de discussão dentro dos momentos destinados às reuniões pedagógicas nas escolas, nas quais a temática central de estudo era a alfabetização e letramento na formação continuada e permanente dos professores. A partir desta compreensão, o trabalho junto às escolas previu, desde o nascimento de sua problemática, o envolvimento dos sujeitos pesquisados, bem como suas constantes participações enquanto sujeitos e autores de construções coletivas.

\footnotetext{
${ }^{5}$ Utilizaremos a nomenclatura $A$ e $B$ para identificar as duas escolas pesquisadas, no universo de pesquisa das seis escolas estas foram escolhidas para compor este trabalho, pois avançaram mais na caminhada e construção das alternativas para discussão e ações no âmbito da alfabetização e letramento dos professores e estudantes. Momento: diálogos em educação, E-ISSN 2316-3100, v. 26, n. 1, p. 96-117, jan./jun. 2017
} 
A pesquisa exploratória fomentou a criação e o desenvolvimento, por parte dos envolvidos diretamente com o Observatório de Educação do campo, a construção de três subprojetos de pesquisa em cada escola participante ${ }^{6}$. No entanto, neste artigo, iremos aprofundar apenas os seguintes subprojetos: Dificuldades de aprendizagem na alfabetização e letramento e A formação de professores alfabetizadores. Ambos os projetos buscaram compreender quais as principais dificuldades no processo de ensino e aprendizagem no nível de alfabetização e letramento dos estudantes, a partir da concepção dos próprios professores e de suas trajetórias docentes.

Desse modo nosso horizonte de pesquisa se desenvolveu no panorama do campo, tendo em sua especificidade econômica a atividade pesqueira e a agricultura familiar, representada no município de Pelotas, ambas situadas na zona rural. A localização da colônia é considerada zona rural de Pelotas, território que inclui a comunidade tradicional de pesca e terras que se destinam as atividades agrícolas como a pecuária e lavoura (principalmente o cultivo de arroz e fumo).

A escola $A$, já passou por inúmeras reformas e ampliações, no que tange a estrutura física: conta atualmente com treze salas de aula, entre elas um laboratório de informática telecentro $^{7}$ - para uso dos alunos e da comunidade em geral, um laboratório de ciências e uma sala de recursos para atendimento de alunos com necessidades especiais. A escola funciona nos períodos matutinos, vespertino e noturno, oferecendo à comunidade o Ensino Fundamental completo, e a Educação de Jovens e Adultos.

O quadro de funcionários na escola, durante a pesquisa, era de 21 profissionais, entre professores, serventes, merendeiras, monitores e secretárias e atende, e tinha em média 448 alunos da rede pública de ensino. Quanto ao público de estudantes atendidos pela escola,

\footnotetext{
${ }^{6}$ Ainda, foram desenvolvidos nas escolas os seguintes subprojetos: na escola $A$, 'Relação Escola e Comunidade: qualificação do letramento na/da comunidade escolar', 'Violência ${ }^{\text {ee }}$ na escola e comunidade: relação com a evasão e reprovação escolar'; e na escola $B$, 'Historicidade da escola a potencialidade do encontro entre Pomeranos e Quilombolas como sujeitos atuantes da comunidade escolar', 'Desafios e possibilidades no processo de formação dos sujeitos na escola do/no campo'.

7 Telecentros comunitários são espaços públicos, oriundos de políticas públicas do Ministério da Pesca e Aqüicultura, providos de computadores conectados à Internet em banda larga. Nesses locais são realizadas atividades, por meio do uso das Tecnologias da Informação e Comunicação (TICs), com o objetivo de promover a inclusão digital e social das comunidades atendidas.

Momento: diálogos em educação, E-ISSN 2316-3100, v. 26, n. 1, p. 96-117, jan./jun. 2017
} 
destacamos que se caracterizam, em sua maior parte, famílias predominantemente oriundas das classes populares.

A Colônia Triunfo, localidade onde se situa a escola $B$ é considerada a localidade mais longe e de difícil acesso do centro da cidade de Pelotas, caracteriza-se especialmente por uma dualidade de etnias, descendentes de Pomeranos e Quilombolas. A atividade econômica da comunidade é de aproximadamente $95 \%$ submetida à monocultura do fumo, e apenas 5\% das famílias se dedicam a agricultura familiar de base camponesa, sendo: leiteira, aviária, hortaliças e frutas. A escola B resiste ao passar dos anos. Ela foi ameaçada de ser fechada inúmeras vezes, por ser considerada muito pequena e por ser distante do centro da cidade. Ela resiste mesmo abandonada pelo poder público e isso por conta do esforço dos professores, que mesmo com dificuldade se disponibilizaram ao longo dos anos à realidade das salas multisseriadas.

No período que esta pesquisa vinha sendo desenvolvida a escola B possuía 14 professores, a escola oferta ensino da pré-escola ao $9^{\circ}$ ano e também, em 2011, passou a ofertar uma turma do Programa de Educação de Jovens e Adultos - PEJA, caracterizado, exclusivamente, pelo acesso de Quilombolas. No total, o atendimento encontrava-se em entorno de 150 alunos, o que não caracteriza mais como uma escola 'pequena'. Os principais impasses, nesta escola, enfrentados por estudantes e professores estão relacionados à infraestrutura precária, pois faltam espaços, como: sala de aula, refeitório, sala de professores, biblioteca, sala para mídias e etc. Além das questões de infraestrutura, os professores identificam três grandes problemas vivenciados pela escola: a) o alto número de crianças com dificuldades no processo de ensino e aprendizagem das etapas de alfabetização, bem como o crescente número de estudantes multirrepetentes; b) as dificuldades no cotidiano da organização do trabalho pedagógico; c) o distanciamento das relações entre a escola e a comunidade.

Já para a escola $A$, embora atualmente, ela se encontra com melhorias no que diz respeito a sua infraestrutura, ainda existe inúmeras limitações que estão ligadas aos altos números de alunos com dificuldades de aprendizagem na leitura e escrita, o que tem gerado um grau significativo de repetência nos últimos anos, e o constante distanciamento entre escola e a comunidade. 


\section{DO RURALISMO PEDAGÓGICO AO PROJETO DE EDUCAÇÃO DO /NO CAMPO}

A construção da educação nos espaços rurais do país é fruto histórico de um espaço de formação do sistema escolar estatal, definido a partir de um projeto de desenvolvimentista da economia para a qualificação da mão de obra da classe trabalhadora do campo, com o intuito de atender as demandas da expansão do capitalismo, principalmente no processo de industrialização do país.

Os camponeses encontram-se refém de uma escolarização de massa e em prol do desenvolvimento da riqueza, e das forças produtivas, direcionadas a uma parcela da sociedade, os donos dos meios de produção. O que se verifica neste histórico é uma consequência de significativas mudanças no mundo agrário, em benefício do desenvolvimento industrial brasileiro e o avanço do sistema capitalista de produção no campo e nas cidades. $\mathrm{O}$ que resultaria não somente no êxodo rural, o processo migratório do campo para a cidade, em busca de melhores condições de vida, mas também, a necessidade de qualificação da mão-deobra para atender às demandas da industrialização e modernização urbana e, consequentemente, rural. Este período caracteriza-se entre 1930 a 1956, conhecido como fase da Revolução Industrial Brasileira.

Nessa perspectiva, a ampliação da escolarização no campo nasce como demanda às respostas do mundo que vinha desenvolvendo-se neste período. As questões relevantes à educação dos camponeses estavam ligadas, por exemplo, ao alto índice de analfabetismo, quase que absoluto, principalmente nas classes populares; com a quase inexistência de escolas públicas no campo, a falta de política pública de ensino, entre outros. A educação então cumpriria o papel de formar estes sujeitos para a demanda do mundo do trabalho que se exigia.

As pautas da educação nos espaços rurais vinham sendo pensadas com o intuito de reverter o quadro de analfabetismo, mas é claro que o conhecimento era de ordem primária e simplificada; a ideia de fixar o homem no campo, para assim atender as exigências de qualificação da força de trabalho e adequar à classe trabalhadora rural a ordem capitalista de produção industrial. 
A origem da escola rural é pensada sob a ótica do grupo de pioneiros do "ruralismo pedagógico", que tinham um projeto de educação voltada às necessidades de desenvolvimento do capitalismo nos espaços rurais do país. (CALAZANS, 1993, p. 23).

Por outro lado, a busca da escola pública que tenha em sua centralidade as necessidades populares, são frutos da luta popular organizada, diretamente ou indiretamente, que sempre esteve relacionada à construção de um projeto popular amplo para a nação. Este projeto educativo de matriz popular tem em seu horizonte uma proposta de educação que tenha na centralidade deste processo as transformações objetivas e subjetivas na direção da valorização da educação dessa população e na possibilidade da superação.

A Educação do Campo enquanto um instrumento alternativo para a classe trabalhadora do campo é forjada principalmente pela demanda coletiva dos movimentos sociais frente à ausência de condições materiais mínimas de sobrevivência e, também, como possibilidade de potencializar o acúmulo da proposta educativa que vinha se formando no âmbito dos movimentos sociais do campo, mais especificamente, do Movimento dos Trabalhadores Rurais Sem Terra - MST, em seus espaços educativos nos acampamentos e assentamentos da reforma agrária. Esse processo apresenta como centralidade a transformação social, ou seja, na qual os trabalhadores do campo se vinculam, organicamente, aos processos de transformação da realidade objetiva, na construção de uma nova ordem, assumindo, assim, em seus processos pedagógicos o caráter político da educação do MST.

$\mathrm{O}$ trabalho ${ }^{8}$, enquanto princípio educativo torna-se o ponto central desses processos, o qual se materializa na construção de método e metodologias que vão ao encontro das necessidades reais dos sujeitos do campo e que afirmam o compromisso com a consciência de classe de educadores e de educandos das escolas nos espaços rurais, como observado em um dos cadernos de educação do Movimento:

\footnotetext{
Em sentido amplo, podemos dizer que a educação é um dos processos de formação da pessoa humana. Processo através do qual as pessoas se inserem numa determinada sociedade, transformando-se e transformando esta sociedade. Por isso ela está sempre ligada com um determinado projeto político e com uma concepção de mundo. (MST, 2005, p.160).
}

\footnotetext{
${ }^{8} \mathrm{O}$ trabalho no sentido ontológico é práxis humana e, então, é a forma pela qual o homem produz a sua própria existência na relação com a natureza e com os outros homens e, assim, nesta relação produzem também a sua humanidade e o conhecimento (LUKÁCS, 1978).

Momento: diálogos em educação, E-ISSN 2316-3100, v. 26, n. 1, p. 96-117, jan./jun. 2017
} 
Compreendendo esse caráter político da educação e, ao mesmo tempo, a necessidade do acesso ao conhecimento historicamente acumulado pela humanidade, a educação se torna pauta na agenda do MST, ampliando a luta por terra e educação. Em 1981, Caldart (2012) apresentou as primeiras iniciativas para a construção de um debate sobre as alternativas para as crianças acampadas em Encruzilhada do Sul/RS, em um processo de luta ao direito à educação nos espaços de reforma agrária.

A Construção da Educação do Campo é uma caminhada longa que exigiu intensos espaços de debates e de articulações com diferentes instituições e organizações da sociedade civil. Mas é em 2002 que ela definitivamente ganha espaço e sua merecida visibilidade pelo poder público. Neste ano é construída as Diretrizes Operacionais para a Educação Básica do Campo, a qual assegura a construção de políticas públicas específicas sobre as pautas históricas dos movimentos sociais do campo, entrando assim para a agenda das ações do Ministério da Educação. Logo após foram construídas secretárias e departamentos específicos que tem enquanto pauta a educação dos povos do campo.

Todos estes avanços são extremamente significativos na busca pela qualidade e acesso à educação nos espaços rurais de nosso país. Além, obviamente, de demonstrar a importância do protagonismo da luta organizada dos movimentos sociais do campo na construção da educação do seu povo. Porém neste momento histórico, o que evidenciamos é que por mais que hoje tenhamos já a concretização de quinze anos das Diretrizes da Educação do Campo e com ela o advento de políticas públicas especificas para estas escolas; o que encontramos são as ausências tanto de infraestrutura como de formação voltada à educação das classes populares do campo. É a partir destas questões que evidenciamos a Educação do Campo enquanto um espaço de resistência e luta.

\section{A EDUCAÇÃO DO CAMPO E A ALFABETIZAÇÃO E LETRAMENTO: NA BUSCA DA CONSTRUÇÃO DA CRITICIDADE}

É a partir do debate da construção de novas formas e conteúdo para a educação do campo, enquanto instrumento de elevação da capacidade de apropriação dos conhecimentos historicamente acumulados, que introduzimos a centralidade do debate na atualidade do papel da alfabetização e do letramento para a escola pública. 
Entendemos que o letramento apesar de ser um termo relativamente novo a ser introduzido na agenda das escolas, ela faz parte de todo um processo de constituição e orientação para as políticas públicas e traz subsídios para a estruturação de uma 'forma e conteúdo' do processo de ensino e aprendizagem dos níveis de alfabetização que também estão sendo demandados para a educação do campo.

O debate sobre a utilização do letramento surgiu no contexto brasileiro a partir do ano de 1980, com forte influência de organizações internacionais, como, o Banco Mundial (BM), o Banco Interamericano de Desenvolvimento (BID), e a Organização das Nações Unidas para a Educação, a Ciência e a Cultura (UNESCO), representando o desenvolvimento do projeto neoliberal para a educação. Com isso, as políticas educacionais, articuladas às políticas públicas mais amplas, cumprem o papel de buscar alternativas e de qualificar o ensino da leitura e da escrita nos países chamados de 'terceiro mundo' como é o caso da América Latina, os quais representam os maiores índices de analfabetos e analfabetos funcionais. No entanto, o referido termo, a partir de então, começa a ser motivo de grandes discussões por pesquisadores da área e por educadores, que aos poucos vão incorporando o fenômeno do letramento no cotidiano das escolas públicas do país, aproximando o letramento as práticas de alfabetização em sala de aula.

A forma como o letramento é incorporado na dinâmica da educação Brasileira, principalmente da escola pública, acontece de forma totalmente diferenciada como, por exemplo, como ela é apropriada nos Estados Unidos. Soares (2003, p. 03), ao diferenciar a forma como o letramento foi apropriado nos diferentes espaços do mundo, apresenta que, "no Brasil os conceitos de alfabetização e letramento se mesclam, se superpõem, frequentemente se confundem". Em países como Estados Unidos, França, etc. e esta diferenciação é o resultado de como foi compreendido o conceito de letramento, e, posteriormente, como ele foi desenvolvido nas escolas.

No Brasil, o letramento foi diretamente associado ao conceito de alfabetização como possibilidade de elevar a capacidade de apropriação do código escrito. Já para os países como Estados Unidos e França, o termo letramento torna-se instrumento capaz de potencializar a utilização do código escrito, a fim de qualificar a educação para as atuais exigências do 
mundo do trabalho. Neste caso, o letramento corresponde a todo processo de formação escolar, e não somente ao processo de alfabetização.

Acredita-se, portanto, que este entendimento de letramento fortemente ligado a alfabetização possa ter ocorrido devido às dificuldades de compreensão por parte dos educadores, ocasionando, por vezes, a desvalorização da alfabetização, ou até mesmo com o intuito de maior fragmentação do conhecimento, como por exemplo, na construção da apropriação técnica - o processo de apropriação e domínio do código escrito, a alfabetização; e a capacidade da construção de uma leitura de mundo mais aprofundada da realidade - o letramento enquanto instrumento de apropriação e domínio de todas as múltiplas relações que possibilitam a leitura da realidade de forma crítica e interventiva. É importante ressaltar que a apropriação do termo letramento é uma prática quase que exclusiva das escolas públicas, as quais são frequentadas, principalmente, por filhos dos trabalhadores. Que seriam estes os que mais necessitariam da apropriação do letramento em suas vidas.

Paulo Freire (1980), apesar de não ter discutido a respeito do letramento, aponta ao longo de suas obras a importância da construção da alfabetização aliada à leitura do mundo de forma consciente e libertadora. Na perspectiva freireana, toda prática de alfabetização é uma prática conscientizadora, que permite ao sujeito, por meio da leitura do mundo e da palavra, ir paulatinamente transformando sua consciência ingênua em consciência crítica. Paulo Freire aplica o conceito de conscientização como elemento indissolúvel do processo de aprendizagem.

A conscientização surge em perspectiva crítica quando comparada a tomada de consciência do homem. O homem, inicialmente, ocupa uma posição ingênua diante da realidade observada, e, então, ao adotar uma posição crítica, chega à conscientização. Esta, por sua vez, desmascara a essência fenomênica do objeto, trazendo ao homem a possibilidade de apreender e analisar de fato a realidade apresentada a ele. Quanto mais conscientização houver, mais nos aproximamos da realidade. (FREIRE, 1980)

Assim, a alfabetização e o letramento, segundo SOARES (2010), é possível, mas, para que isso aconteça, é preciso que o professor permita ao estudante vivenciar práticas sociais reais de leitura e escrita, para não se restringir apenas ao domínio do código. Além de garantir 
ao estudante um maior tempo de escolarização, tendo em vista a ampliação de suas possibilidades de aprender no âmbito de uma cultura letrada.

O que acabamos de escrever indica a necessidade de termos uma formação de professores que esteja ligada a realidade, e que exerçam o papel de mediadores entre a leitura sociocultural ampla e a particularidade dos contextos dos estudantes. O exercício dessa mediação é o que possibilitará a articulação entre a alfabetização e o letramento, viabilizando para os estudantes da escola pública, que na sua maioria são filhos de trabalhadores, o que repetidamente se diz e escreve: uma formação crítica, na direção da educação como prática da liberdade (FREIRE, 2001).

\section{O COTIDIANO DAS PRÁtiCAS ESCOLARES DE ALFABETIZAÇÃo E LETRAMENTO NAS ESCOLAS DO CAMPO}

Os projetos desenvolvidos na formação de professores tiveram como objetivo central o levantamento de análises e hipóteses formuladas pelos próprios professores da escola sobre o baixo rendimento dos seus alunos. Procurou-se que tais proposições de pesquisa partissem da realidade empírica dos professores e dos estudantes das escolas, bem como os problemas que envolvem o cotidiano da organização do trabalho pedagógico. Uma das situações - limite é a grande quantidade de alunos com dificuldades de aprendizagem, principalmente no que tange a leitura e a escrita. Tal situação tem gerado um grau significativo de repetência e multirrepetência nos últimos anos, as quais atribuídas ao processo de alfabetização.

Desta maneira, os projetos do Observatório desenvolvidos nas escolas tiveram como propósito, segundo a investigação-ação, construir coletivamente ações pedagógicas, a partir da formação de grupos de estudos para discussão e reflexão sobre a prática pedagógica dos professores, bem como a troca de experiências. Durante esses momentos também foi possível desenvolver, junto aos professores dos anos iniciais, estratégias de trabalho coletivo, a fim de ampliar os conhecimentos e qualificar as práticas sobre alfabetização e letramento.

$\mathrm{Na}$ escola A, foram observadas e acompanhadas três turmas de primeiro e quintos anos, compostas por estudantes entre sete e doze anos de idade, durante o período de seis meses nos anos de 2012 a 2014. A grande maioria dos estudantes investigados é residente da Colônia, porém, três destes residem em uma granja, a granja se diferencia, pois, os alunos são filhos de trabalhadores da plantação de arroz, enquanto os demais são filhos de pescadores 
artesanais. O nível sócio cultural da Colônia corresponde a sujeitos que vivem principalmente da pesca artesanal, com suas especificidades de crenças, valores e costumes oriundos de sua origem pesqueira. A localidade possui condições precárias de recursos e opções voltadas ao conforto e qualidade de vida aos que nela habitam.

$\mathrm{Na}$ escola $\mathrm{B}$, o processo de pesquisa deu-se na turma de terceiro ano, devido ao fato de ser o espaço de maior ocorrência de alunos multirrepetentes da escola. Os sujeitos da pesquisa foram cinco estudantes, todos com idade entre dez e doze anos. No decorrer da pesquisa foram realizadas entrevistas com as professoras e com os responsáveis dos estudantes, e avaliações diagnósticas com os estudantes, no começo de 2012 e de 2014. As avaliações diagnósticas tiveram o intuito de levantar questões referentes ao processo em que os alunos se encontravam na aquisição da leitura e da escrita e quais os limites no processo de aprendizagem.

Utilizou-se os mesmos eixos de análise das observações para ambas escolas, tais como: conhecer os materiais didáticos utilizados pelos professores, observar a organização e a postura do professor e do estudante na sala de aula, analisar a relação professor-estudante, e por fim, o desempenho dos estudantes. As entrevistas tiveram como eixos de análise: a formação do professor, as dificuldades encontradas no cotidiano pedagógico, sua representação sobre o processo de ensino-aprendizagem, e suas trajetórias docentes levando em conta suas histórias de vida.

Com relação ao nível de formação dos professores pesquisados de ambas as escolas ressaltaram que a totalidade das profissionais alfabetizadoras entrevistadas é do sexo feminino com idade entre 26 - 52 anos, constatamos que grande parte possui ensino superior (graduação), como podemos visualizar no gráfico abaixo. 


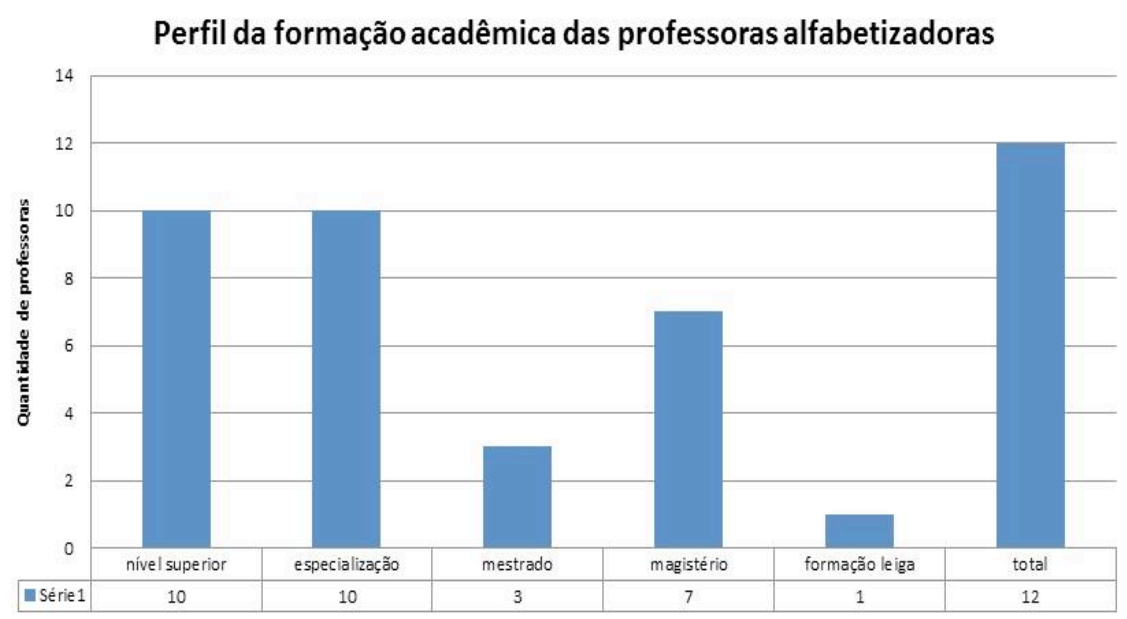

Figura 01: Coleta de dados realizada a partir da pesquisa-ação desenvolvida nas escolas investigadas.

Tal análise é significativa para mostrar que as dificuldades encontradas pelas professoras, no trabalho com a alfabetização e letramento, não estão totalmente relacionadas à falta de formação. No entanto, a proposta curricular dos cursos pode não atender as necessidades de formação das mesmas no que diz respeito às discussões acerca da alfabetização e letramento na educação do campo.

Ainda em relação à formação das professoras entrevistadas, objetivou-se saber se elas possuem cursos de pós-graduação, no que verificamos no gráfico acima que uma grande porcentagem tem concluído os estudos na pós-graduação na forma de especialização, mas outro fato que instiga é que apenas três professoras têm mestrado na área da educação.

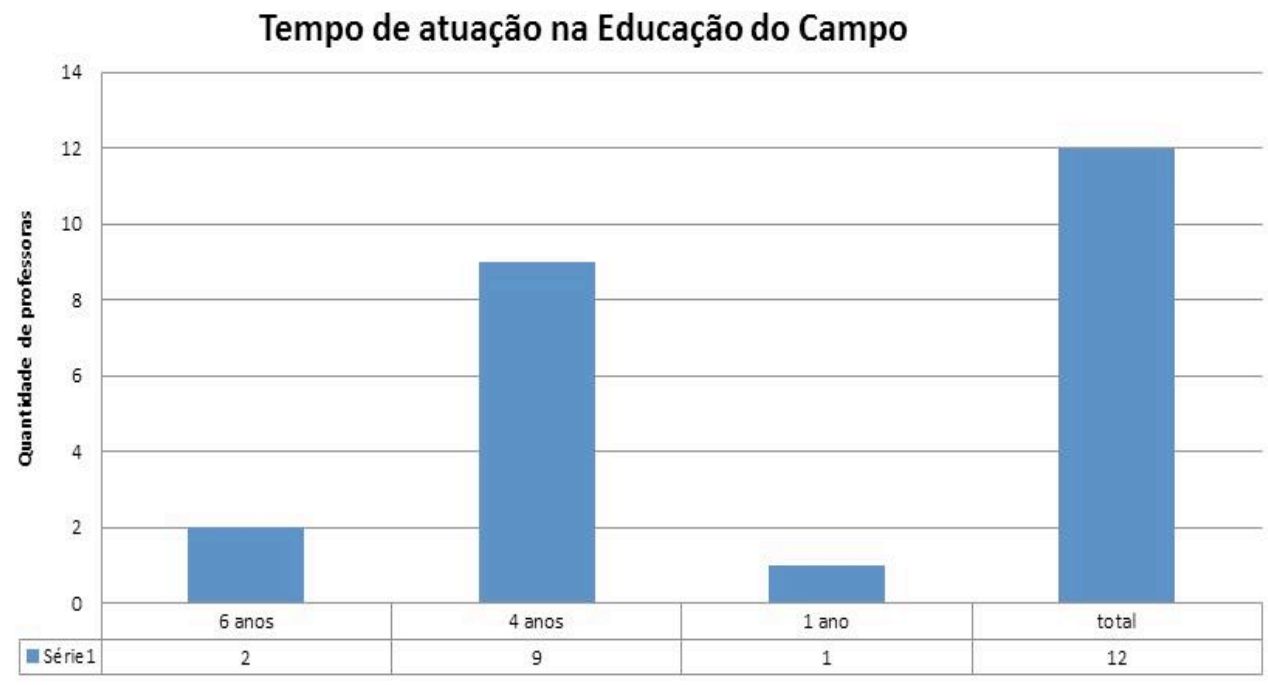

Figura 02: Coleta de dados realizada a partir da pesquisa-ação desenvolvida nas escolas investigadas. Momento: diálogos em educação, E-ISSN 2316-3100, v. 26, n. 1, p. 96-117, jan./jun. 2017 
A maioria das professoras desconhecia a especificidade da Educação do Campo, e relatam que vieram a descobrir a partir do projeto de pesquisa desenvolvido pelo Observatório da Educação do Campo. O gráfico demonstra que o tempo de atuação em Educação do Campo das professoras é relativamente curto, o maior tempo de seis anos e o mínimo de um ano. As docentes, ainda afirmaram que nos últimos três anos, anteriores ao projeto aproximadamente $2 \%$ das professoras disseram ter realizado cursos voltados para a temática da alfabetização, e nenhuma delas afirma ter participado de formação especifica sobre a educação do campo.

Em relação ao nível de proximidade do grupo docente com a comunidade de modo geral, ainda é muito incipiente, a metade do número de professores trabalha 40 horas na escola, destes $60 \%$ atuam a mais de 10 anos na escola. A maioria das professoras alfabetizadoras mora na cidade, e o restante reside na zona rural, algumas professoras relataram que mesmo morando na mesma localidade que os estudantes, por vezes, se sentem como estrangeiros na comunidade, pela dificuldade de articulação do conhecimento prévio sobre os costumes, cultura e organização comunitária com as disciplinas e conteúdos ministrados na escola.

Assim, é possível observar a necessidade de conhecer a realidade, não somente o contexto geográfico, mas também compreender teoricamente as questões pedagógicas que implicam na concepção de Educação do Campo. Em um de nossos encontros, foi enfática a fala de uma professora:

Faz cinco anos que trabalho nessa escola, porém nunca me preocupei em conhecer a comunidade, vinha, dava minha aula, de forma a cumprir meu conteúdo, e voltava para casa, sei que isso precisava mudar e tenho tentado modificar aos poucos, mas não é fácil mudar todo jeito como tu dá atua aula há anos e o pior colocar toda essa realidade deles na hora de alfabetizar me parece bem mais difícil do que na matemática, nas ciências, por exemplo.

O afastamento dos professores em geral, das escolas investigadas com a comunidade ainda, era forte nos primeiros anos da pesquisa. Um exemplo disto é o relato de uma das professoras alfabetizadoras, quando iniciamos a pesquisa e as formulações de hipótese $d a$ origem das dificuldades dos estudantes:

Os alunos aqui têm muita dificuldade na alfabetização, eles custam a aprender acho que é por que a maioria deles trabalha e é envolvido nas atividades com as famílias, e sabe como é alguns pais nem são alfabetizados. Uns alunos são bons, mas a 
maioria não, também depende da turma e do ano, mas a maioria tem muita dificuldade mesmo.

Fator preocupante este na formação do quadro de professores que estão inseridos na realidade do campo, pois a grande maioria destes é oriunda da zona urbana, e mesmo os professores ligados à zona rural normalmente tem dificuldades na ampliação das relações com a comunidade e ensino escolar, pela formação urbanocêntrica recebida durante toda sua trajetória docente e pela representação ingênua de que as comunidades tradicionais são atrasadas, de que o trabalho prejudica no processo de ensino-aprendizagem, herança do ruralismo pedagógico na formação dos professores do campo.

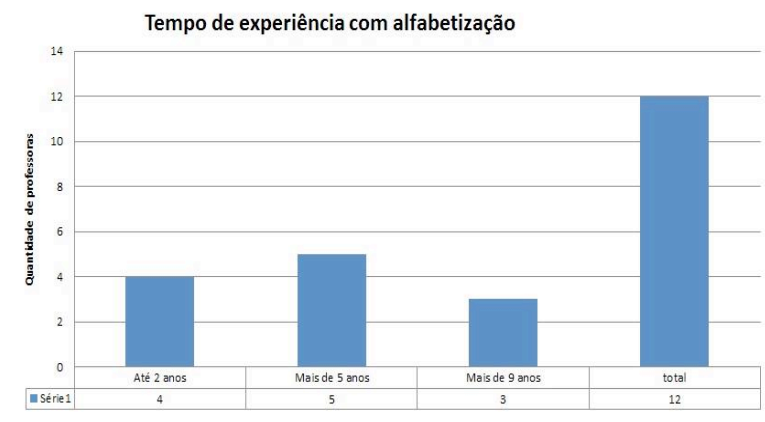

Figura 03: Coleta de dados realizada a partir da pesquisa-ação desenvolvida nas escolas investigadas.

No caso da experiência com alfabetização a maioria das professoras tem um bom tempo de experiência na alfabetização de crianças e adultos, enquanto apenas cinco professoras têm até dois anos de jovem experiência nas classes de alfabetização. Partindo assim, dos dados (qualitativos e quantitativos) verificou-se que as professoras, pertencentes às escolas investigadas, não exploram uma postura crítica dos estudantes, somente técnicas que permitam e estimulam à lógica da alfabetização mecânica.

Não é possível perceber relação entre a alfabetização e o letramento, as professoras, embora involuntariamente e inconscientemente, parecem reproduzir no cotidiano escolar esse processo. Acreditamos que os percalços se deem também pela ausência de um aprofundamento teórico sobre o letramento e sobre como conduzir, na prática pedagógica, o processo de estabelecimento das relações entre ambos, letramento e alfabetização.

Pode-se, além disso, levantar a hipótese, embora de modo inicial, que o próprio nível de letramento das professoras, até o momento, é limitado. O que significa dizer que elas também possuem dificuldade na realização de uma leitura mais reflexiva e crítica da 
realidade. Ademais, constatou-se a importância de questionar o processo de formação que as professoras tiveram em seus percursos educativos, uma vez que, ambas as professoras, das aulas foram observadas no projeto, possuem graduação e especialização. Portanto, é perceptível a necessidade de formação sistemática das professoras e com profundidade, essa formação deveria permiti-las compreender as relações entre a alfabetização e o letramento no processo ensino e aprendizagem.

Os resultados de nossas investigações indicam que o processo de ensino-aprendizagem desenvolvido em sala de aula compreende-se como a alfabetização. Isso coloca interrogações sobre o domínio teórico das professoras a respeito da relação entre alfabetização e letramento, assim como do seu próprio percurso educativo. O isolamento no trabalho docente é outro elemento que acaba dificultando o trabalho coletivo, a socialização e articulação das propostas pedagógicas.

\section{OS DESDOBRAMENTOS DA PESQUISA-AÇÃO NA ESCOLA E NA COMUNIDADE}

Assim, conforme a coleta e a análise de dados, algumas inquietações se apresentaram para a continuidade dessa pesquisa: como ser um professor crítico e com isso desenvolver a criticidade, se o processo de formação inicial não foi embasado nessa perspectiva? Como um professor pode avançar na visão social de mundo se, na maioria das vezes, sua visão social de mundo serve para legitimar e justificar ou defender a atual ordem social? Como avançar na lógica dialética, se as instituições formadoras em sua maioria seguem a lógica formal cartesiana de ensino, pesquisa e extensão?

A partir dessas indagações e das problemáticas investigadas e evidenciadas neste texto, desde o início da pesquisa em 2012, procurou-se planejar junto às comunidades escolares ações para, a princípio, amenizar, problematizar e desconstruir tais entraves de maneira coletiva, ou seja, no cotidiano do trabalho pedagógico. As estratégias de ações, durante os anos de 2012- 2013 -2014, foram direcionadas para consolidação dos projetos, tanto no âmbito das escolas, como nas comunidades pesquisadas, para que os sujeitos da pesquisa pudessem contribuir com as demandas futuras provenientes dessa pesquisa-ação.

A respeito das ações realizadas nas escolas; para a escola $\mathrm{A}$ as atividades do período de 2012 a 2013 foram fortemente destacadas pela comunidade e pelo grupo de professoras, como as oficinas de alfabetização e letramento. As oficinas foram elaboradas a partir do Momento: diálogos em educação, E-ISSN 2316-3100, v. 26, n. 1, p. 96-117, jan./jun. 2017 
diagnóstico das entrevistas com as professoras, quando o grupo priorizou temáticas que teriam relevância para auxiliar no processo pedagógico de alfabetização e letramento, como: concepções de alfabetização e letramento; materiais didáticos no processo da alfabetização; temas geradores e Paulo Freire; importância da biblioteca no processo de alfabetização; troca de experiências com escolas convidadas. Essas oficinas foram organizadas em dois momentos: discussão teórica e oficina prática. Além disso, este espaço possibilitou a construção coletiva de duas cartilhas sobre a formação de professores alfabetizadores da Educação do Campo.

Durante o trabalho na escola, destacaram-se, além das oficinas, os seminários sobre violência, os quais motivaram a construção dos Fóruns de combate à violência escolar, o espaço foi autogerido pelos pais e pela escola, para que de forma permanente se elaborasse alternativas para amenizar e problematizar os impactos da violência local no processo de ensino-aprendizagem dos estudantes e das famílias. A formação continuada com todos os professores da escola também foi um espaço permanente planejado com os professores.

No ano de 2013, o núcleo do Observatório que vinha atuando junto ao grupo do currículo, do ano fundamental foi convidado para participar do processo de alteração do Projeto Político Pedagógico (PPP) da escola, a partir destes encontros foram destacadas como demandas da escola as seguintes formações com todo grupo de professores da escola: Projeto de escola do campo, a questão agrária e da pesca artesanal no Brasil; Gestão e participação; Currículo, planejamento e proposta interdisciplinar; Violência no espaço escolar. Em consequência dessas formações foram construídos e planejados juntos aos professores alguns materiais didáticos, como: cartilhas e documentários, para tal realização, foram feitas articulações com Sindicato dos Pescadores, Associação de bairro, Igreja Católica, que tem forte papel na comunidade, e secretarias do município e do estado, assim como outras instituições, as quais disponibilizaram recursos humanos, o que dinamizou e criou redes de possibilidades efetivas para as questões em pauta.

Durante os quatro anos do processo de pesquisa-ação na escola B; as atividades realizadas a fim de buscar alternativas possíveis nas soluções das problemáticas da alfabetização e do letramento vivenciadas pelos educadores foram: a) um grupo permanente de estudos, com diferentes temáticas como: Alfabetização de jovens e adultos; Educação 
popular na escola pública; Métodos de alfabetização, alfabetização/letramento; Relação escola e comunidade; Métodos de alfabetização; A construção da Educação do Campo, entre outros, b) acompanhamento sistemático do processo de aprendizagem dos educandos pesquisados, acompanhado pela educadora da turma c) oficinas com diferentes temáticas e oportunidades de socialização de práticas positivas vivenciadas pelos educadores; d) construção de materiais didáticos pedagógicos, como o livro intitulado A Colônia Triunfo conta as suas histórias, que apresenta o histórico da comunidade local, em forma de entrevistas, relatos de educadores, poemas, cantigas, lendas, ritos, mitos e curiosidades que envolvem a cultura da Colônia do Triunfo. Este material foi elaborado mediante a colaboração da comunidade escolar, da comunidade local e pesquisadores. Ele caracteriza-se como resultado do processo de investigação-ação dos subprojetos que se desenvolveram na escola.

Também fruto deste movimento, destaca-se a elaboração de um documentário, com momentos da pesquisa e análise do contexto deste território por professores, pesquisadores e líderes da comunidade. Outro material importante construído neste ano foi uma cartilha de alfabetização, Livro Didático da Escola B. Foi evidenciada a necessidade da organização de um material específico para o desenvolvimento das questões pedagógicas relacionadas ao contexto da localidade nos processos de ensino-aprendizagem; e) a realização de seminários $e$ cine comunidades, os quais tinham a intenção de ampliar o processo educativo da escola para toda a comunidade local. Nos dois eventos realizados pela escola, buscou-se trazer temáticas de interesses comuns e que possibilitassem a ampliação da visão social de mundo, possibilitando assim um espaço de diálogo crítico e problematizador.

É importante evidenciar que ambas as ações desenvolvidas no projeto são frutos de um planejamento coletivo, ou seja, entre os sujeitos da escola e os pesquisadores que compunham o grupo de pesquisa de cada instituição de ensino. Todas as ações são resultado de um exercício continuo, de um lado, evidenciando os limites, e de outro, buscando possíveis soluções, demonstrando a importância do protagonismo da escola e da comunidade na construção do seu processo educativo, enquanto sujeitos de direitos e possibilidades. Assim a pesquisa-ação perpassa a simples coleta de dados, o academicismo. Porém, conforme bem salientado por Thiollent (1986), não é um mero ativismo, pois se pretende com a pesquisaação aumentar o conhecimento dos sujeitos envolvidos, assim "não se trata de apenas resolver 
um problema imediato e sim desenvolver a consciência da coletividade nos planos políticos ou culturais a respeito dos problemas que enfrentam".

\section{CONSIDERAÇÕES FINAIS}

As pesquisas realizadas pelo Observatório da Educação do Campo, núcleo do Rio Grande do Sul, permitiu conhecer e analisar as práticas pedagógicas das escolas do campo, partindo do diagnóstico realizado nas investigações. Conforme as problemáticas evidenciadas no percurso dessa pesquisa-ação, os processos desenvolvidos nas escolas contribuíram para a melhoria das condições de análise da aprendizagem dos estudantes, trazendo nesse movimento a comunidade para discutir suas problemáticas na relação escola e comunidade.

Neste sentido, outra importante contribuição desta investigação foi à possibilidade da construção de sujeitos 'autônomos e investigadores' da sua prática pedagógica, para que através de estratégias de resistência com base na educação popular se propusessem a superação e problematização de algumas das suas situações-limites, na direção da construção de uma consciência de si para si.

\section{REFERÊNCIAS BIBLIOGRÁFICAS}

BRANDÃO, Carlos. Pesquisa Participante. $2^{\text {a }}$ Edição. Editora Brasiliense S.A São Paulo Brasil.1982.

CALAZANS, Maria. Para compreender a educação do Estado no meio rural. In: DAMASCENO, Maria n. \& THERRIEN, Jacques (org.). Educação e escola no campo. Campinas, Papirus, 1993.

CALDART, Roseli; Molina, Mônica; MUNARIM, Antônio; ROCHA, Eliene Novaes. Notas para Análise do Momento Atual da Educação do Campo. In. Fórum Nacional de Educação do Campo (FONEC). Anais. Seminário Nacional - BSB, 15 a 17 de agosto de 2012.

FREIRE, Paulo. Ação cultural para a liberdade e outros escritos. São Paulo: Paz e Terra 2001.

Educação Como Prática da Liberdade. Rio de Janeiro: Editora Paz e Terra, 1980.

FRIGOTTO, G.O enfoque da dialética materialista histórica na pesquisa educacional. In: FAZENDA, Ivani (org.). Metodologia da pesquisa educacional. São Paulo: Cortez, 2000. p. 71-90.

JARA, Oscar. Para sistematizar experiências. Trad. Maria Viviana V. Resende. 2. ed., Revista. - Brasília: MMA, 2006. 
LUKÁCS, György. As bases ontológicas do pensamento e da atividade do homem. Temas de Ciências Humanas, tradução de Carlos Nelson Coutinho, São Paulo: Livraria Editora Ciências Humanas, 1978.

MELlO, Marco. Pesquisa Participante e Educação Popular: Da Intenção ao Gesto. Editora Isis. Diálogos-Pesquisa e Assessoria em Educação Popular; IPPOA Instituto Popular porto Alegre,2005.

MST, Dossiê MST Escola: Documentos e estudos 1990 - 2001. Caderno de Educação, $\mathrm{n}^{0} 13$ Edição Especial, 2005.

SOARES, Magda. Alfabetização e letramento. São Paulo: Contexto, 2010

THIOLLENT, Michel. Metodologia da Pesquisa-ação. São Paulo: Cortez: Autores Associados, 1986.

TRIVIÑOS, Augusto. Introdução à pesquisa em ciências sociais: a pesquisa qualitativa em educação. São Paulo: Editora Atlas, 1987. 